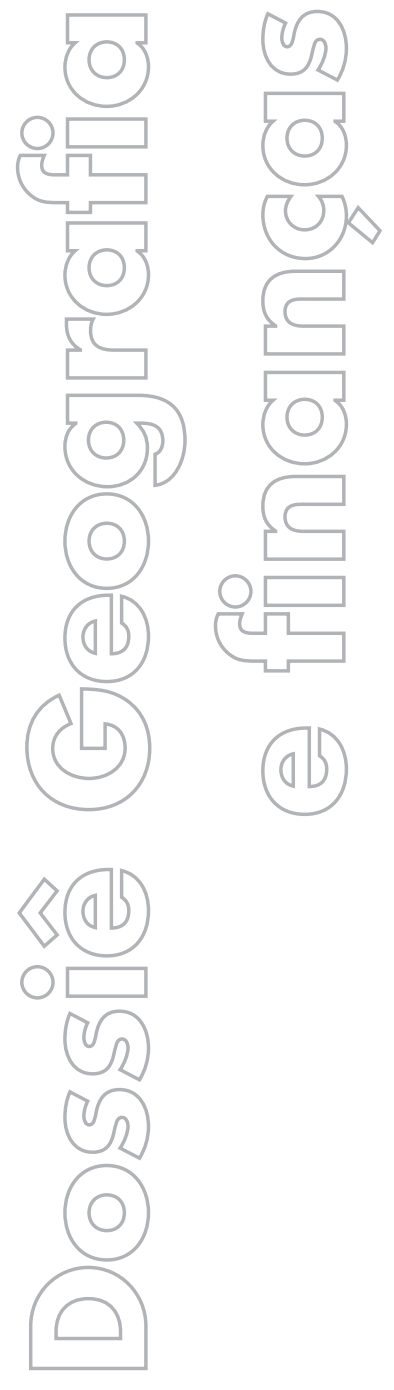

revista

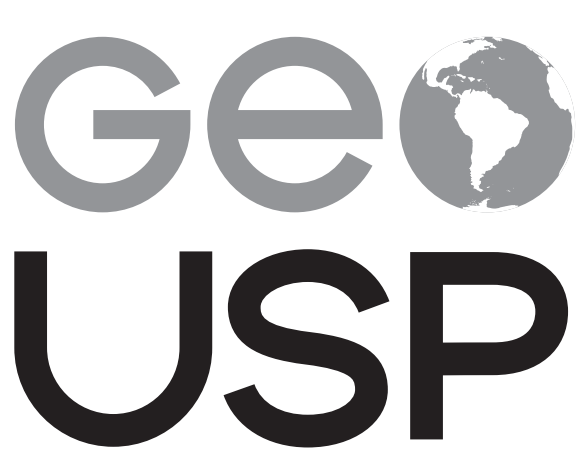

espaço e tempo

Volume $21 \cdot n^{\circ} 2(2017)$

\section{Interações entre} componentes regionais do sistema bancário nacional

\author{
Fernando Nogueira Costa \\ Unicamp
}

p. $425-442$

Como citar este artigo:

COSTA, F. N. Interações entre componentes regionais do sistema bancário nacional. Geousp - Espaço e Tempo (Online), v. 21, n. 2, p. 425-442, agosto. 2017. ISSN 2179-0892.

Disponível em: < http://www.revistas.usp.br/geousp/ article/view/134540>. doi: 10.11606/issn.2179-0892. geousp.2017.134540.

\section{(c) $(1) \Theta$}

Este artigo está licenciado sob a Creative Commons Attribution 4.0 License. 


\title{
Interações entre componentes regionais do sistema bancário nacional
}

\section{Resumo}

Autores pós-keynesianos esperavam que a atividade bancária agravasse a concentração regional no Brasil. Minha hipótese é que "a organização do espaço geoeconômico brasileiro influencia o crédito", em vez de pressupor que "as finanças vêm influenciando a organização do espaço geográfico brasileiro". Há uma tendência histórica de concentração locacional de redes e sedes de agências bancárias, atraídas por captação de riqueza financeira. Mas contrabalança-se o destino do crédito dirigido pela demanda, no caso de bancos privados, com crédito direcionado, no caso de bancos públicos. A ação bancária pública é orientada também pelo conhecimento desse efeito compensatório da desigualdade regional.

Palavras-chave: Bancos. Atividade regional. Crescimento. Desenvolvimento. Mudanças.

\section{Interactions between Regional Component of the National Banking System}

\begin{abstract}
Post Keynesian authors expected that banking worsen the regional concentration in Brazil. My hypothesis is that "the organization of the Brazilian geo-economic space influences the credit" instead of assuming that "finances have influenced the organization of the Brazilian geographical space". There are historical trend locational concentration of head offices and branch networks of banks, attracted by capturing financial wealth. But directed credit in the case of public banks counterbalances to the credit destination driven by demand in the case of private banks. The public bank action is also guided by the knowledge of this compensatory effect of regional inequality.
\end{abstract}

Keywords: Banks. Regional Economic Activity. Growth. Development. Changes. 


\section{Introdução}

Analistas pós-keynesianos - (Amado, 1997, 1998; Cavalcante; Crocco; Jayme Jr., 2004; Crocco, 2004; Crocco et al., 2003, 2004, 2005; Crocco; Figueiredo, 2009; Fernandes et al., 2007; Jayme Jr.; Crocco, 2005, 2010) - advertiram quanto às perspectivas de a atividade bancária agravar a concentração regional no Brasil. Elas se apresentavam na Era Neoliberal anterior a 2003. Porém, na análise da Era Social-desenvolvimentista posterior, em vez de pressupor que "as finanças vêm influenciando a organização do espaço geográfico brasileiro", minha hipótese é que ocorre uma interação e/ou retroalimentação: "a organização do espaço geoeconômico brasileiro influencia o crédito".

Analisando os principais traços do modus operandi dos bancos dominantes em escala nacional, deduzo que a concentração regional por sedes e redes de agências dos bancos se dá em busca de captação da riqueza financeira onde seus detentores residem. A reação resultante desse processo de realimentação por intermédio do qual uma ação é controlada pelo conhecimento do efeito de suas respostas caracteriza a tendência histórica de concentração bancária regional por captação de riqueza financeira. Mas o destino do crédito é dirigido tanto pela demanda quanto por política pública.

A oferta de crédito com recursos livres de bancos, sejam privados, sejam públicos, é efetivada pela demanda. $\bigcirc$ crédito com recursos direcionados, concedido por bancos públicos, é orientado por política pública.

A Ciência da Complexidade permite ver mais claramente o fenômeno macroscópico emergente de interações microscópicas entre a dinâmica de mercado e a de política socioeconômica. Ela parte da visão do Todo, percebendo-o como um fenômeno macroscópico de emergência a partir de interações de componentes, no caso institucionais e regionais, de um Sistema Complexo nacional.

A auto-organização do espaço geoeconômico brasileiro influencia hoje o crédito, mais do que o contrário. A desigualdade regional da riqueza determina a escolha das sedes e de rede de agências dos bancos particulares. A busca de correção dessa desigualdade por meio de políticas públicas, em conjunto com a demanda efetiva por crédito, influencia o direcionamento do crédito dos bancos públicos federais e dos bancos de desenvolvimento regional. Nesse Sistema Complexo, há dependência de trajetória com retroalimentação que políticas públicas tentam regular, mas não conseguem a determinar de maneira irreversível.

Não resenharei, em razão de espaço delimitado, a literatura pós-keynesiana a respeito preferência pela liquidez dos bancos e da preferência pela liquidez do público, que apontava a tendência de concentração do crédito regional na economia brasileira. Contraporei minha opção examinando, primeiro, um caso real de alocação de ativos e passivos por um banco público e, após, a proporção da riqueza pessoal no Brasil captada em cada grande região e estados destacados.

Com esta análise, esboçarei a estratégia locacional das sedes e redes de agências dos bancos para captação de riqueza financeira. Ao contrário da hipótese contumaz - o financiamento bancário agrava a concentração regional -, adotarei a hipótese de que há influência do espaço geoeconômico, seja desenvolvido, seja subdesenvolvido, sobre o crédito. Se os bancos privados respondem apenas à demanda de crédito, mostrarei que os bancos públicos enfren- 
tam a desigualdade regional com políticas públicas compensatórias. Em outras palavras, é necessária uma análise institucionalista da atuação dos bancos brasileiros por origem de capital, diferenciando-a do padrão internacional.

\section{Hipóteses pós-keynesianas sobre concentração bancária regional}

Por que, como queremos demonstrar adiante, as previsões pós-keynesianas falharam? À primeira vista, porque os enunciados sobre o mundo real não eram verdadeiros. $\bigcirc$ conceito-chave para alguns economistas pós-keynesianos - preferência pela liquidez - não é uma proposição realista em um sistema de circulação monetária bancária.

Percebe-se, na literatura pós-keynesiana brasileira, que o atributo de liquidez dos ativos financeiros é estipulado em termos relativos, seguindo a teoria do portfólio a la Hicks. Preferência pela liquidez em termos restritos a la Keynes refere-se à retenção de moeda improdutível por mão de obra. Só então a moeda retida, de maneira ociosa, por uma massa expressiva de agentes econômicos, provocaria desemprego. Essa demanda de dinheiro por motivo de precaução ou especulação quanto ao futuro não seria atendida por meio de maior produção material de moeda. Já "quase-moedas" recebedoras de juros constituem passivos que lastreiam ativos, tanto empréstimos quanto títulos, inclusive títulos de dívida pública, portanto, suas retenções não geram desemprego.

que quero dizer com isso? Reter depósitos à vista por parte de correntistas não impede a circulação monetária via bancos. Se eles não gastam dinheiro, outros o fazem, endividando-se. Desde que ocorra demanda por crédito, empréstimos multiplicam depósitos. Estes depósitos captados pelo sistema bancário lastreiam novos empréstimos em um processo só regulado pela exigência de recolhimento compulsório por parte da Autoridade Monetária e/ou delimitado pelo saque de papel-moeda por parte dos correntistas.

"Armadilha de Liquidez" é um processo identificado por Keynes apenas em uma grande depressão. Nesse caso extraordinário, o aumento da oferta de moeda - recentemente apelidado de "afrouxamento monetário" - não tem por consequência a queda da taxa de juros de mercado, mas sim provoca incremento na retenção geral de saldos monetários ociosos e/ou reservas bancárias. Considera-se esse um evento fora do comum, quando só então ocorre "preferência pela liquidez absoluta".

Em condições normais, aumento da oferta de moeda resulta em aumento dos preços dos títulos financeiros, na medida em que os agentes econômicos procuram adquirir ativos e não permanecer com moeda, dado o custo de oportunidade de moeda não receber juros. A elevação dos preços (valores de mercado) de títulos prefixados provoca tendência de queda na taxa de juros efetiva no mercado financeiro. Incentiva o investimento produtivo.

\section{Administração de ativos e passivos (ALM) por banco público}

Minha alegação contra a argumentação pós-keynesiana está baseada em reflexão teórica - "crédito é dirigido pela demanda" segundo a linha de pensamento pós-keynesiana conhecida como horizontalista (Moore, 1988; Costa, 1993) - e em experiência prática - tesouraria de banco faz operações compromissadas com todo o saldo líquido diário a partir da verificação 
pelos sistemas de informações de todas as entradas e saídas de caixa, inclusive os desembolsos por empréstimos concedidos. Cabe apresentar alguma evidência empírica para comprová-la. O custo de oportunidade de reter moeda, seja strictu sensu, seja quase-moeda, leva sim à preferência por rentabilidade (e não por liquidez) por parte dos bancos, considerando a avaliação de risco dos potenciais clientes.

A reflexão pós-keynesiana a respeito da preferência pela liquidez do público [PLP = (depósitos a vista) / (depósitos totais)] e preferência pela liquidez dos bancos [PLB = (depósitos a vista) / (operações de crédito)] remete, respectivamente, à avaliação do caráter da riqueza pessoal no Brasil mantida em depósitos à vista ou de poupança e à alocação de ativos e passivos (ALM, sigla em inglês de Asset and Liability Management) dos bancos.

Tomando o exemplo real de ALM de um banco público, no caso da Caixa, em dezembro de 2006, testemunho que a alta administração deste banco contratava consultoria para ver como se conseguiria demanda de crédito nas condições de mercado. As operações comerciais (crédito) tinham um spread de 37 pontos percentuais (pp), enquanto o caixa central tinha 7,41 pp e a tesouraria apenas 0,77 pp, menor até do que o de compulsório / exigibilidades (1,51 pp) e de políticas públicas (0,92 pp). Entretanto, no final de 2006, a Tesouraria retinha 50\% do Ativo; o Caixa Central, 4\%; as Políticas Públicas, 28\%; os Compulsórios/Exigibilidades, 12\%; e Operações Comerciais só 6\%.

Com base nesses resultados (ex-post), é racional afirmar que isso comprova que "banco tem preferência por liquidez e raciona crédito"? Não se concede mais crédito só quando não há mais demanda por ele nas condições de mercado exigidas.

Nesse exemplo real de ALM de um banco público, a Política Pública em Habitação e Saneamento com Recursos do Fundo de Garantia de Tempo de Serviço (FGTS), Crédito Imobiliário com Recursos de Depósitos de Poupança, e Operações de Agente de Fomento, toda ela tinha custo médio ponderado de 68\% do Certificado de Depósito Interbancário (CDI) e rendimento médio ponderado de 75\% do CDI. Por sua vez, Operações de Crédito Comercial tinham custo de $98 \%$ do CDI e rendimento de 379\% do CDI. Em outras palavras, fazia-se política pública como missão social e compensava-se seu baixo spread (0,92 pp) com a ação comercial com elevado spread (37 pp). Sob critério estrito de rentabilidade, é lógico que a preferência seria por esta última. Mas não havia demanda de crédito para elevá-la...

Compulsórios e Exigibilidades custavam 57\% e rendiam 68\% do CDI. Tesouraria tinha custo de 100,2\% e rendimento de 106,1\% do CDI. Caixa Central, respectivamente, 33\% e $89 \%$ do CDI.

Os passivos da Tesouraria - com duration de um dia - eram Operações Compromissadas e Captação no Mercado Aberto como dealer, cujo custo médio ponderado era 100,67\% do CDI. $\bigcirc$ maior volume de recursos era tomado do Caixa Central. $\bigcirc$ total de ativos da Tesouraria - títulos de dívida pública com duration médio de 564 dias - rendiam 106,6\% do CDI. Logo, o spread em pontos percentuais da diferença de juros pagos e juros recebidos era muito menor do que o de operações de crédito comercial. Ressalto, novamente, que o banco não concedia mais crédito comercial porque não conseguia demanda e não porque tinha preferência pela liquidez. 
total geral de ativos do banco era remunerado a 104\% do CDI e tinha duration de 904 dias, equivalente a dois anos e meio. $\bigcirc$ passivo total, por sua vez, era remunerado a 58\% do CDI e exigia contínua administração do hiato de duration. Em outras palavras, o lucro bancário vinha, principalmente, do grande valor aplicado em um baixo spread médio ponderado. Se conseguisse demanda para tal, nas condições de mercado solicitadas, o banco certamente apreciaria elevar esse spread com o maior diferencial de juros obtidos em operações de crédito comercial.

Quando a taxa de juros é elevada, com a presença de mais ativos em longo prazo que passivos, o valor de mercado da carteira de ativos (A) reduz-se mais do que o valor de mercado da carteira de passivos $(\mathrm{P}): \triangle \mathrm{PL}=\Delta \mathrm{A}-\Delta \mathrm{P}$. Com hiato de prazo, por exemplo, de dois anos e meio, aumento de um ponto percentual das taxas de juros pode fazer com que os acionistas sofram forte redução em seu patrimônio. Melhor maneira de imunizar-se seria fazer com que o hiato de prazo, a diferença entre o prazo médio de vencimento de ativos e passivos, torne-se igual a zero. Porém, nesse caso, haveria uma troca na proporção entre maximização de retorno e minimização de risco.

Com análise das participações relativas dos principais ativos e passivos nos balanços dos maiores bancos pode-se verificar se há diferenças na administração de ativos e passivos por origem de capital. Em pesquisa com base nos balanços de bancos publicados pelo Banco Central do Brasil no fim de 2015 (BCB, [s.d.]), constata-se que em nenhum desses casos de bancos relevantes a participação da carteira de empréstimos é inferior à da carteira de títulos e valores mobiliários (TVM). Disponibilidade indicaria a preferência pela liquidez strictu sensu, ou seja, refere-se a um percentual muito diminuto (menos de 2\%) dos ativos bancários. Operações de crédito por parte dos grandes bancos privados giravam em torno de 1/3 dos ativos, enquanto eram 41\% no BNDES, 47\% no Banco do Brasil e 57\% na Caixa. Carteira de títulos correspondia a cerca de 1/5 dos ativos dos privados e a menor percentual nos públicos: Caixa, 15\%; BNDES, 11\% e Banco do Brasil, 9\%.

Quanto ao indicador de PLP (preferência pela liquidez do público), mais relevante para operações de crédito será analisar, na próxima seção, a relação entre depósitos totais e Fundos de Investimentos Financeiros (FIF), ou seja, a competição entre captação de funding e a administração de recursos de terceiros por parte de bancos. Por ora, vale observar que os bancos se utilizam de outras fontes de financiamento na composição passiva, além dos depósitos à vista e de poupança com baixo custo, em que o Banco do Brasil e a Caixa têm Market-share, respectivamente, em torno de 33\%, como o "dinheiro comprado" (CDB, LCI e LCA), as Letras Financeiras e os Repasses.

Os grandes bancos costumam fazer Captações no Mercado Aberto em volume maior do que aplicam em Títulos e Valores Mobiliários. Logo, carregando parte da carteira de empréstimos com refinanciamento contínuo em curtíssimo prazo no mercado interbancário, eles demonstram não preferência pela liquidez, mas sim por rentabilidade. Caixa e BNDES dependem também de repasses de outras fontes de financiamento, respectivamente, FGTS e FAT. Santander e HSBC, provavelmente, complementam esse funding com repasses externos.

Para avaliação do Resultado Bruto de Intermediação Financeira (RBIF) e Outras Receitas e Despesas Operacionais, é interessante destacar o peso muito superior, em torno de 60\% do total, de Receitas de Operações de Crédito face às de Operações com Títulos e Valores 
Mobiliários, com menos de 40\% do RBIF. No final de 2015, registrou-se prejuízo com Operações com Derivativos dos bancos privados. No caso do HSBC, que acabou sendo vendido para o Bradesco, o prejuízo com Operações de Câmbio foi significativo. O surpreendente é que, no terceiro trimestre de 2015, os RBIF de todos os maiores bancos listados, exceto na Caixa e no ponto de equilibrio do HSBC, foram negativos.

Buscou-se compensação com Outras Receitas e Despesas Operacionais. Nestas receitas, destaca-se o percentual do Resultado de Participação em Empresas Coligadas da maioria dos bancos: Bradesco (73\%), BNDES (71\%), BTG-Pactual (55\%), Itaú (38\%), Banco do Brasil (30\%). Só a Caixa tem pouca (7\%) e o Santander nenhuma receita com coligadas. Por sua vez, a Caixa se destaca na obtenção de Receita de Prestação de Serviços, em especial, ao setor público.

Em termos de despesas, devido à característica de executores de políticas públicas, as participações de Despesas de Pessoal no total de Despesas Operacionais dos bancos públicos são superiores: Caixa com 37\%, Banco do Brasil com 33\%, BNDES com 31\%. As dos privados são menores: Bradesco com 28\%, Itaú com 19\% e Santander com 13\%.

A conclusão parcial dessa seção, depois de examinados um exemplo real de ALM e os dados de balanços dos maiores bancos brasileiros, é que os analistas pós-keynesianos que creem em preferência pela liquidez por parte dos bancos necessitam rever seus conceitos. Partindo de falsas premissas, não é surpreendente que tenham errado em suas predições a respeito do agravamento da concentração regional no Brasil por causa da concentração bancária e, supostamente, das operações de crédito.

\section{Estratégia locacional das sedes e rede de agências dos bancos para capta- ção de riqueza financeira}

Para examinar a concentração da riqueza financeira, o Censo Semestral da Caderneta de Poupança de junho de 2014, cuja fonte primária de dados é o Fundo Garantidor de Crédito (FGC) (BCB, [s.d.]), mostra que, em junho de 1999, existiam 42.796 .773 clientes com saldo total de $R \$ 111,60$ bilhões. Em dezembro de 2015, existiam 129.595.909 clientes com saldo total de $\mathrm{R} \$$ 605,06 bilhões em depósitos de poupança, sendo que 67.415 .660 (52\%) deles tinham menos do que $R \$ 100,00$ na caderneta de poupança (média per capita de $R \$ 17,00$ ), então, esta ou substituía a conta corrente, pois não cobrava tarifas bancárias, ou era inativa. Mas houve um processo de inclusão financeira muito importante - haja visto o saldo total desses depósitos - de acesso popular a bancos e crédito, cujos principais protagonistas foram os bancos públicos federais, no caso, Caixa e Banco do Brasil.

Com o propósito de evitar distorção estatística, a Anbima ([s.d.]) desconsiderava em seu ranking de riqueza financeira esses 67,4 milhões depositantes que tinham $R \$ 1,1$ bilhão com menos do que $R \$ 100,00$ per capita na caderneta de poupança. A concentração da riqueza financeira destacava-se quando se comparava os depositantes de poupança. Em dezembro de 2015, segundo Relatório do Private e varejo da Anbima ([s.d.]), os 109.894 clientes Private Banking detinham apenas R $\$ 1,48$ bilhões em depósitos de poupança. Os 1.919.900 depositantes de poupança do varejo de alta renda possuíam $R \$ 71,81$ bilhões com média per capita de $R \$$ 
37.402,00. Por sua vez, os 60.260 .349 clientes do varejo tradicional depositavam $\mathrm{R} \$ 531,77$ bilhões (média per capita de $\mathrm{R} \$ 8.825,00$ ) em poupança. Essa "classe média baixa" gerou 88\% dos $R \$ 603,6$ bilhões da fonte de financiamento imobiliário a si própria.

Somados, os depósitos de poupança ainda constituem o principal funding do Sistema Financeiro Nacional (SFN) com 29\% do total de R \$2,1 trilhões investidos por pessoas físicas (PF). Considerando-os, emergia do varejo tradicional ("os mais pobres") o maior saldo financeiro ( $R$ \$ 821,8 bilhões), superior ao do varejo de alta renda ( $R$ \$ 569, 9 bilhões) e ao do Private Banking (R $\$ 712,5$ bilhões). "Dinheiro de pobre" tem importância.

Pode-se considerar esses depósitos de poupança indicador de preferência pela liquidez?! Será que eles não são apenas sintoma de um comportamento inercial ("deixa estar") quanto à preferência por produto financeiro mais simples e barato, inclusive pelo conservadorismo de depositantes de poupança com perfil etário mais elevado?

Parte dos títulos e valores mobiliários serve de lastro para empréstimos, mas os títulos de dívida pública são carregados, em parte, por Fundos de Investimentos Financeiros (FIF). Considerando os 6.323.376 clientes do varejo tradicional (66\%) com saldo per capita de $\mathrm{R} \$ 45.871,00$, os 3.124 .715 clientes de varejo de alta renda (33\%) com $R \$ 159.403,00$, e os 109.894 clientes de alta fortuna (1\%) com $R$ \$ 6,5 milhões per capita, eram apenas 9.557 .985 investidores PF nesses produtos financeiros em dezembro de 2015. Porém, seus investimentos, desconsiderando os depósitos de poupança, somavam $R$ \$1,5 trilhão.

Essa concentração financeira determina a localização da captação de passivos bancários ou de clientes para a Administração de Recursos de Terceiros por parte dos bancos. No caso das grandes fortunas, é gritante a concentração de Ativos sob Administração (AuM, na sigla em inglês) por domicílio. Entre os 52.050 Grupos Econômicos, que representavam 109.894 clientes (soma dos CPF e CNPJ) atendidos pelo Private Banking, na estatística consolidada da Anbima ([s.d.]) em dezembro de 2015, os moradores no Sudeste representavam 75,6\%, sendo $51,7 \%$ no estado de São Paulo. Os "sudestinos" detinham 78,2\% do valor administrado (R\$ 651,42 bilhões).

Comparando o quadro, elaborado pela Anbima ([s.d.]), com saldos das aplicações financeiras por domicilios dos clientes, em dezembro de 2015, com a concentração econômica por PIB regional (calculado pelo IBGE), percebe-se que, embora o Sudeste tenha $78 \%$ da riqueza financeira contra 55\% do PIB, os percentuais do estoque de riqueza para cada uma das demais grandes regiões são inferiores aos dos fluxos de valores agregados sob forma do PIB regional: no Centro-Oeste: 4,7\% contra 9\%; no Sul, 16\% contra 17\%; no Nordeste, 9,3\% contra 14\%; no Norte, $1,6 \%$ contra $5 \%$.

Então, a valorização maior dos ativos financeiros ocorre no "centro", mas em empreendimentos da "periferia" gera-se um fluxo de renda em proporção superior à do estoque de riqueza financeira lá captada. Talvez os grandes investidores do centro financeiro também obtenham rendas, devido às propriedades imobiliárias, e lucros, extraídos de empreendimentos empresariais, em outros estados.

A dedução é que os grandes bancos não podem deixar de centralizar suas captações financeiras na região central do país (Sudeste), notadamente na cidade de São Paulo, mesmo porque também a distribuição de produtos para o varejo de alta renda concentra-se na região 
Sudeste com 73,6\%. No varejo tradicional, a correspondência entre participações regionais na riqueza financeira e no PIB são mais próximas, respectivamente, Sudeste: 56,7\% X 55\%; Sul: 20,9\% X 17\%; Centro-Oeste: 6,2\% X 9\%; Nordeste: 13,5\% X 14\%; Norte: 2,8\% X 5\%.

São menores as sobras dos fluxos de renda desses clientes do varejo tradicional que se transformam em saldos financeiros. Já no varejo de alta renda, há desproporção mais parecida com a do Private Banking. Por essa análise regional da concentração dos clientes por produtos financeiros, comprova-se a primeira parte da hipótese de que a concentração locacional bancária se justifica pela captação mais do que pelas operações de crédito.

Quando se inclui os depósitos de poupança, a distribuição regional do número de clientes sofre a influência do peso avassalador do número de seus depositantes. Mesmo a Anbima ([s.d.]) desconsiderando 67 milhões de clientes com saldo igual ou menor do que $R \$ 100,00$, ainda outros restam 62 milhões, dos quais 18 milhões habitam o estado de São Paulo e quase 13 milhões a região Nordeste. Sendo assim, em vez de destacar que 53\% dos clientes investidores em todos os produtos do varejo moram no Sudeste, é melhor salientar que são $73 \%$ dos clientes de varejo de alta renda e 52\% do varejo tradicional de média e baixa renda. Em São Paulo, habitam, respectivamente, 50\% e 29\%. Justifica-se assim a localização das sedes e dos principais negócios dos grandes bancos privados.

Na história bancária brasileira (Costa, 2012), os grandes bancos privados nacionais cresceram por meio de fusões e aquisições bancárias, ganhando assim abrangência nacional, apesar de sempre privilegiarem a disputa de negócios na região mais dinâmica e no centro financeiro, isto é, na capital de São Paulo. A estratégia locacional deles foi crescer aproveitando oportunidades de aquisições de concorrentes em São Paulo e de bancos com nichos regionais, inclusive os bancos estaduais quando foram privatizados, ganhando então maior escala nacional.

Segundo a Pesquisa da Atividade Bancária no Estado de São Paulo, realizada pelo Seade nos anos 1990 (Costa; Marinho, 1995), o estado de São Paulo possuía cerca de 46\% e 33\% da clientela bancária nacional - pessoas físicas (PF) e pessoas jurídicas (PJ), respectivamente.

Conferi a situação atual pela agregação dos dados de balancetes por municípios e estados, disponíveis no site do Banco Central do Brasil. Processando uma imensa planilha, verifiquei que a capital de São Paulo concentrava $67 \%$ das operações de crédito e $77 \%$ do passivo total no estado em novembro de 2015. No caso de incluir-se Osasco, cidade pertencente à Grande São Paulo, devido à centralização do processamento de informações na Cidade de Deus do Bradesco, eram, respectivamente, $81 \%$ e $95 \%$.

Eram 2.568 agências (36\% do total do estado e 11,25\% do total nacional) na capital de São Paulo naquela data. $\bigcirc$ estado somava 7.129 ou 31\% do total do país. Além da cidade de São Paulo, a concentração ocorria na Grande São Paulo (ABCDOG e Barueri), Santos, Jundiaí, Campinas, Sorocaba, Araraquara, Ribeirão Preto, São José do Rio Preto e São José dos Campos.

Os maiores bancos dominam amplamente o mercado bancário da capital de São Paulo com suas agências - Itaú-Unibanco: 580; Bradesco: 512; Santander: 482; Banco do Brasil: 391; Caixa Econômica Federal: 298; HSBC: 87; Citibank: 60; Safra: 35. Elas somam 2.445, representando $95 \%$ do total da capital. 
A economia brasileira segue a "regra do terço", pois se reparte em três terços segundo as últimas Contas Regionais, referentes a 2013, elaboradas pelo IBGE (2014): 32,1\% de São Paulo; 33\% da soma de Rio de Janeiro (11,8\%), Minas Gerais (9,2\%), Paraná (6,3\%) e Rio Grande do Sul (6,2\%); e 34\% dos vinte e dois outros estados. Entretanto, há uma notável constância nas participações percentuais das grandes regiões no PIB entre 2010 e 2013: Sudeste com cerca de 55\%; Sul, 17\%; Nordeste, 14\%; Centro-Oeste, 9\%; Norte, 5\%.

Em 2002, a participação do PIB do estado de São Paulo era 34,6\%. Desde então, foi caindo gradualmente até 32,1\% em 2013.

Como o sistema bancário brasileiro se conformou a essa concentração regional? Adequando-se perfeitamente a ela, em um processo de retroalimentação, porém não cumulativo, pois a atuação nacional dos bancos públicos ameniza a centralização.

Segundo Torres (2014, p. 4):

[...] as sedes das maiores empresas estão localizadas nas capitais brasileiras do Sul e Sudeste - o Distrito Federal é a única localidade que se destaca fora dessas regiões, por concentrar empresas estatais. A Região Metropolitana de São Paulo contava com a maior aglomeração de sedes de grandes corporações, abrigando 98 grupos empresariais em 2012,49\% do total observado, o que corresponde a uma receita bruta superior a $R$ \$ 1,5 trilhão. $\bigcirc$ município de São Paulo é o grande polo concentrador das sedes dessas organizações, com 44\% do total nacional de corporações registradas nessa amostra e $41 \%$ do valor da receita bruta declarado por elas. $\bigcirc$ segundo maior grupamento de sedes de corporações encontra-se na Região Metropolitana do Rio de Janeiro, que contava com 28 empresas (14\% do total) e uma receita bruta total de 745 bilhões (25\%). Belo Horizonte, Porto Alegre, Curitiba e Brasilia são as outras regiões metropolitanas que concentravam mais do que cinco sedes de grandes grupos econômicos. A ausência na gestão pública de um olhar para a questão da chamada 'competitividade urbana' pode induzir perda de sedes de organizações de grande porte, com resultados significativos no longo prazo.

Ele alerta que o comando da área operacional (produção), embora também seja essencial para as organizações, em alguns casos opera de modo descentralizado, localizado junto às principais fábricas (ou agências bancárias no caso em análise) do grupo. Em bancos, são as Superintendências de Negócios regionais.

Mais do que a difusão de conhecimentos e a presença do pool de mão de obra com profissionais de alta qualificação, é estratégico estar com sede no centro de negócios financeiros, onde estão presentes também Bolsa de Valores, Banco Central, CVM, Febraban, CIP, Abecip, ABECS, Cetip, Selic, Anbima etc. Estar próximo de sedes de outras grandes organizações e instituições governamentais parece ser de maior relevância para a decisão sobre a localização da sede de uma organização bancária possuidora de rede nacional de agências.

Em 2015, havia 158 bancos operando na economia brasileira, sendo que 101 tinham sedes no estado de São Paulo, ou seja, 64\%. Na região Sudeste, somavam 125 (79\%). 
Entretanto, o sistema bancário nacional atingiu uma boa cobertura territorial, em um país semicontinental (48\% da América do Sul), pois dos 5.888 municípios apenas 300 municípios (5,4\%) estão sem nenhuma dependência bancária, sendo que 202 estão no Nordeste e 35 no Norte. Estima-se que $20 \%$ da população estão dispersos em zonas de baixa concentração demográfica, morando em 4.074 municípios com até 20 mil habitantes. Apenas 255 municípios têm mais que 100 mil habitantes, vivendo neles cerca de $51 \%$ dos brasileiros.

Vale observar que o país tem 13 metrópoles com mais de um milhão de habitantes e a $4^{a}$ maior megalópole mundial (e maior do Hemisfério Sul) na região entre Campos-RJ e Campinas-SP, inclusive parte da Zona da Mata de Minas Gerais. Nela, em apenas 0,97\% do território nacional, reúnem-se 232 municípios em três estados, cerca de 23\% da população brasileira com renda per capita 55\% acima da média, gerando 35\% do PIB.

Uma megalópole é uma extensa região urbanizada, pluripolarizada por metrópoles com conurbação, forte integração econômica e intensos fluxos de pessoas, mercadorias e capitais. Nela há concentração bancária, pois se trata de uma imensa zona urbanizada que forma um mercado consumidor de grandes dimensões, atraindo atividades econômicas diversificadas e de alta capitalização.

Na próxima seção, em vez de pressupor que "as finanças vêm influenciando a organização do espaço geográfico brasileiro", minha hipótese será que "a organização do espaço geoeconômico brasileiro influencia o crédito". Em outras palavras, a demanda dirige a oferta de crédito. Em compensação, crédito às obras públicas e às políticas sociais ativas fomentam essa demanda. As operações de crédito, recentemente, adaptaram-se à concentração econômica regional, porém, não a agravando como os analistas pós-keynesianos previam, por causa dos bancos públicos.

\section{Influência do espaço geoeconômico sobre o crédito}

Um argumento comum nesse debate sobre concentração bancária regional é a alegação que o estado de São Paulo possui 7.132 agências, isto é, 31,2\% do total nacional de 22.826, proporção maior do que a de sua população: 21,7\%. A notável aproximação daquele percentual com a proporção do PIB $(32,1 \%)$ indica uma correlação que, hipoteticamente, apontaria uma causalidade: concentração econômica causa concentração financeira. Mas é possível inverter a hipótese: esta causa aquela. Vamos testar esta última, lembrando que a hipótese de que "a demanda efetiva a oferta de crédito" diz respeito à primeira causalidade. No entanto, trata-se de um sistema complexo com processo de realimentação.

Nordeste tem 27,7\% da população com apenas 15,9\% do total de agências. Parece que o público-alvo dos bancos, tanto PF, quanto PJ, se localiza mais em regiões de maior renda per capita como o Sudeste (52,3\% das agências versus $41,9 \%$ da população) e o Sul (18,8\% versus $14,3 \%)$.

Será que, então, é fundamental ter sede de qualquer banco em sua região ou seu município como reivindicam lideranças locais? Nem sempre correlação indica causalidade. No sistema bancário brasileiro, "meia dúzia de cinco bancos" (já que o Bradesco adquiriu o HSBC) detém mais de 2/3 dos ativos totais do sistema bancário brasileiro, 78\% dos depósitos totais, e obtiveram 62\% do lucro líquido. Banco do Brasil, Bradesco, Itaú, Caixa e Santander (o grupo BBICS) somam 20.760 ou $90 \%$ do total de agências. 
Quando comparamos as participações relativas desses agregados por tipo de controle acionário (origem de capital), impressiona a aproximação entre proporções de ativos e de agências: públicos, respectivamente 44,6\% e 44,3\%; privados nacionais, 37,7\% e 39,4\%; e estrangeiros, $17,7 \%$ e 16,3\%. Porém, entre os ativos dos bancos públicos consta que o BNDES, banco de desenvolvimento sem rede própria de agências, contribui com $11,2 \%$ dos ativos de todo o sistema bancário. Em escala nacional, Banco do Brasil e Caixa compensam essa sua carência de agências. A dedução lógica é que mais vale para o desenvolvimento local receber financiamento do BNDES, do Banco do Brasil ou da Caixa para algum empreendimento do que ter uma sede bancária em sua cidade.

Essa proposição é confirmada por estatísticas derivadas dos balanços dos bancos, publicados pelo Banco Central do Brasil, em que se registra a maior possibilidade de receber crédito de algum banco dos BBICS e/ou do BNDES, já que eles fizeram 82\% das operações de crédito registradas contabilmente em setembro de 2015. Considerando cada Market-share em crédito, bancos públicos concederam $53,6 \%$, privados nacionais, $33,4 \%$, e estrangeiros, $12,9 \%$. Nessa conjuntura de crise, os públicos tiveram uma atuação anticíclica, financiando os empreendimentos realizados e irrigando de liquidez os mercados de todas regiões. A aversão ao risco explica a retração dos privados? Ou foi "a preferência pela liquidez dos bancos"?

Os bancos privados nacionais tinham 46,6\% do valor total das carteiras de Títulos e Valores Mobiliários, os estrangeiros, 22,2\%, e os públicos, 31,1\%. Então, é necessário qualificar os argumentos, pois se essas carteiras são supostas indicadoras de "preferências pela liquidez", elas são de porte distinto por origem de capital. Políticas públicas não são feitas em função das expectativas do mercado, mas sim para alcançar os objetivos socioeconômicos planejados. Cabe falar em preferência pela liquidez no caso de bancos públicos?

Outro dado impressionante (e antes raro) está no número de clientes das carteiras de crédito dos oitos maiores bancos, neste caso, incluindo o Votorantim (quase 50\% das ações possuídas pelo Banco do Brasil) e o Pan (idem em relação à Caixa). Eles atenderam 87\% dos clientes, açambarcando $90 \%$ das operações de crédito. Os bancos acima da 20 a posição nesse ranking de número de clientes e operações de crédito são bancos de atacado ou têm dimensão local. Não são bancos de varejo com rede de escala nacional.

De que adianta ter um pequeno banqueiro próximo, se ele só cuida da gestão de sua fortuna e de seus acionistas majoritários? Há "bancos" e "banquetas"...

Na verdade, cada um dos BBICS tem seu "nicho de mercado". Suas participações no mercado de crédito destacam a "cultura da empresa" de cada qual. Destaque imediato, são os 74\% de Market-share no crédito imobiliário da Caixa. Mesmo que o Banco do Brasil tenha iniciado a operar também essa atividade e eleve a soma de bancos públicos para 82,5\% do financiamento habitacional, a Caixa é um tradicional "banco imobiliário". Também o Banco do Brasil é o costumeiro fornecedor de crédito agrícola: $61 \%$ do total. $\bigcirc$ Itaú se destaca em cartão de crédito (ou crédito rotativo) com 35\% e crédito no exterior com 34\%. Como a mais forte coligada do conglomerado Bradesco é a seguradora e o Banco Central não a consolida no conglomerado como atividade bancária, este grande banco privado nacional não é dominante em nenhum desses nichos de mercado, embora tenha razoável participação em quase todos, exceto crédito ao exterior. $\bigcirc$ Santander (com 18\%) disputa a liderança do crédito à aquisição 
de veículos com o Votorantim (17\%) e, dada sua origem estrangeira, tem $20 \%$ do crédito ao exterior. Aliás, este é o foco quase exclusivo do BTG Pactual, pois ele domina 39\% desse mercado e dedica $96 \%$ de sua atividade bancária a exterior.

A contrapartida dessa visão dos Market-share diz respeito à principal modalidade de crédito PF em cada um dos dez maiores bancos. Por exemplo, o financiamento habitacional representa $76 \%$ do total da carteira de crédito da Caixa, tendo além disso só alguma expressão (12\%) o empréstimo com consignação em folha de pagamento. O Banco do Brasil, assim como o Itaú (22\%) e o Bradesco (24\%), também se dedica bem (22\%) a esse empréstimo com baixo risco. Mas seu negócio preferencial é o crédito rural e agroindustrial que constitui $43 \%$ de sua carteira. Para o Itaú, 27\% de seu crédito é concedido via cartões. Quase 1/4 (24\%) do crédito do Santander é financiamento de veículos, enquanto o Votorantim com $81 \%$ dedica-se quase exclusivamente a esse negócio bancário. Por sua vez, o BTG-Pactual concentra (96\%) sua atividade de crédito à PF no exterior. HSBC privilegia empréstimo sem consignação enquanto Banrisul e Pan com consignação.

Por ser um crédito concedido em longo prazo, o financiamento habitacional constitui a maior parcela (31\%) da soma das carteiras PF de todos os bancos. Em segundo lugar, vem o empréstimo com consignação em folha de pagamento com $17 \%$.

No que se refere ao crédito à PJ, pela ordem do ranking de Market-share nas distintas modalidades, o Banco do Brasil domina investimento (51\%), além do crédito rural e agroindustrial (25\%). Mais da metade (55\%) do financiamento à infraestrutura é concedido pelo BNDES. A preferência do Itaú é o crédito à PJ no exterior, pois controla 39\%. O Bradesco tem boa parcela do capital de giro rotativo (22\%) e maior do crédito habitacional para PJ (31\%), provavelmente, construtoras e incorporadoras. A Caixa tem 1/5 desse tipo de cliente enquanto o Santander tem 16\%.

Por origem de capital, bancos públicos dominam amplamente o crédito à PJ para investimento (58\%), outros créditos (59\%), financiamento à infraestrutura (81\%). Bancos privados nacionais são expressivos nas demais operações de crédito, mas em conjunto dominam capital de giro rotativo (56,5\%), crédito rural e agroindustrial (50,3\%), financiamento habitacional à PJ (50,5\%), e a empresas no exterior (76\%). Os bancos estrangeiros só superam os nacionais, ligeiramente, em operações com recebíveis (42\% contra 41\%).

Quando analisamos a carteira de crédito ativa por região geográfica (local da sede e destino do crédito em percentual), conseguimos vislumbrar o "grau de bairrismo" de bancos locais e/ou regionais. O banco "bairrista" - aquele que devota afeição especial ou exagerada à sua cidade ou ao seu estado e tem atitudes de menosprezo para com as demais cidades ou os demais estados - está principalmente no Nordeste, na medida que $72 \%$ de suas operações de crédito destinam-se à própria região. Os bancos com sedes no Sul concedem 46\% do total de seu crédito na própria região. Diferentemente, o Banco da Amazônia (Basa, um banco público) concede $37 \%$ de suas operações de crédito a clientes do Sudeste. Provavelmente, estes operam na Zona Franca de Manaus por causa dos incentivos fiscais e creditícios. $\bigcirc$ único banco autenticamente do Centro-Oeste é o BRB (Banco Regional de Brasilia). Ele concentra 94\% de suas operações de crédito na própria região. Os demais sediados em Brasília são públicos federais: o Bancoob concentra 61\% de seu crédito no Sudeste; a Caixa, 50\%; e o Banco do Brasil, 47\%. 
caso dos bancos sediados no Sudeste é distinto? Por exemplo, Banestes (96\%) e o Banco de Desenvolvimento do Espírito Santo (99\%) concentram quase a totalidade de suas operações na própria região, assim com o BDMG (97\%). Há três bancos cariocas 100\% cariocas. E o BTG Pactual, sediado no Rio de Janeiro, concede 85\% no exterior. Mas, desconsiderando os bancos sediados no estado de São Paulo, 54\% das operações de crédito dos bancos do restante do Sudeste são na própria região. Os paulistas, como um todo, colocam 43\% no Sudeste e $26 \%$ no exterior.

Novamente, o que é relevante não é esse "grau de bairrismo", mas sim o desempenho nacional de cada um dos membros do BBICS. Além deles, é importante verificar que o BNDES destina $61 \%$ ao Sudeste, 11\% ao Nordeste, 9\% ao Centro-Oeste, $7 \%$ ao Sul e 2\% ao Norte. Outros bancos públicos federais, embora sediados no Distrito Federal, têm uma atuação nacional, pois nos casos do Banco do Brasil e da Caixa concedem, respectivamente, 47\% e 50\% no Sudeste, 17\% e 18\% no Sul, 11\% e 16\% no Nordeste, 11\% e 12\% no Centro-Oeste, 4\% e $4 \%$ no Norte. $\bigcirc$ BB concede $10 \%$ ao exterior, provavelmente para empresas exportadoras brasileiras ou importadoras estrangeiras de produtos nacionais.

Por sua vez, os membros privados do BBICS não são "bairristas", exceto o estrangeiro Santander, que concentra 55\% de seu crédito no Sudeste (que corresponde ao percentual o PIB da região), mas isso deve ser por causa da aquisição da rede de agências do antigo Banespa, banco do governo paulista com quase a totalidade da rede de suas agências localizada no estado de São Paulo. Já o Bradesco e o Itaú concedem, respectivamente, 39\% e 38\% ao Sudeste e 30\% e 38\% ao exterior. Não são bairristas nem xenófobos - quem manifesta aversão, desconfiança ou temor por pessoas estranhas ao seu meio ou cultura, ou pelo que é incomum ou vem de fora do país.

Dessas constatações se deduz não só que o grupo do BBICS, com a exceção do Santander, tem escala nacional, isto é, suas operações de crédito alcançam todo o território nacional. Eles não têm "preferências pela liquidez diferenciadas de acordo cada estado ou região" como argumentam os citados pós-keynesianos. Na verdade, a oferta de crédito atende à demanda propiciada pelo crescimento econômico de cada região.

Aparentemente, "a demanda dirige a oferta de crédito", pois no total da carteira de crédito ativa por região geográfica, desconsiderando a "região não informada" e o "crédito ao exterior", os percentuais dela são muito próximos dos percentuais regionais do PIB em 2013 (último ano de cálculo das Contas Regionais). No caso do Sudeste é igual: 55\% de PIB e de crédito; no Centro-Oeste, respectivamente, 9\% e 11\%; no Sul, 17\% e 18\%; no Nordeste, 14\% e 13\%; no Norte, 5\% e 4\%. Veja as duas últimas linhas do Quadro 1.

Quando observamos a mesma carteira por tipo de controle acionário (também no Quadro 1), os públicos tinham Market share de 49\%, em setembro de 2015, os privados nacionais $37 \%$ e os estrangeiros 14\%. Mas os destinos do crédito de cada qual eram muito distintos. Ao exterior, $76 \%$ eram concedidos por privados nacionais. No território nacional, os bancos públicos predominavam em todas as regiões: Sudeste (53\%), Centro-Oeste (61\%), Nordeste (60\%), Norte (57\%) e Sul (55\%). Em outras palavras, suas atuações em crédito não levaram ao agravamento da concentração regional do PIB, como os analistas previam como efeito das decisões de crédito supostamente orientadas por preferência pela liquidez. 


\section{Quadro 1}

Carteira de crédito ativa - por região geográfica

Tipo de controle acionário

Total Geral Sudeste Centro-oeste Nordeste Norte Sul Não Inf. Exterior

$\%$ de Público

$48,9 \% \quad 53,4 \%$

$61,6 \%$

$59,8 \% \quad 56,9 \% \quad 55,2 \%$

$48,3 \% \quad 12,5 \%$

$\%$ de Privado Nacional

$37,1 \% \quad 30,7 \%$

$24,6 \%$

$28,5 \% \quad 31,0 \% \quad 31,0 \%$

$43,0 \% \quad 75,9 \%$

$\%$ de Privado Estrangeiro

$14,0 \% \quad 15,8 \%$

$13,8 \%$

$11,7 \% \quad 12,1 \% \quad 13,8 \%$

$8,6 \% \quad 11,7 \%$

Total

$100,0 \% \quad 100,0 \%$

$100,0 \%$

$100,0 \% 100,0 \% \quad 100,0 \% \quad 100,0 \% \quad 100,0 \%$

Tipo de controle acionário

$\begin{array}{rrrrrrrr}\text { Total Geral Sudeste } & \text { Centro-oeste } & \text { Nordeste } & \text { Norte } & \text { Sul } & \text { Não Inf. Exterior } \\ 100 & 50 & 11 & 13 & 3 & 17 & 2 & 4\end{array}$

$\%$ de Público

$\%$ de Privado Nacional

$\%$ de Privado Estrangeiro

$100 \quad 38$

$100 \quad 51$

Total

$100 \quad 45$

$100 \quad 55$

Total Recalculado Sem RNI e Exterior

PIB Regional em 2013 (segundo IBGE)

100

55

Data-base: Setembro 2015 - SCR processado até: 30/11/2015

Valores monetários em $\mathrm{R} \$$ mil

fonte: Sistema de Informações de Crédito (BCB, [s.d.]).

Então, uma abordagem institucionalista (por origem de capital) e estruturalista (por características socioeconômicas) parece dar melhores explicações para o crédito destinado por região demográfica. Por exemplo, o Quadro XXXIV, obtido na nota para imprensa de Política Monetária e Operações de Crédito do SFN (BCB, 2016), aponta que em todas as regiões, exceto Sudeste, o crédito às PF foi superior ao concedido às PJ. Entretanto, este representava $53 \%$ do crédito total, ou seja, só a demanda de crédito por parte de PJ no Sudeste representou $33 \%$ do saldo do total em dezembro de 2015. Nessa região, o crédito concedido à PF representou $22 \%$, totalizando $55,1 \%$ do total.

Mais surpreendente, para quem se fiou nas predições das análises pós-keynesianas da década passada, é que, a partir do Quadro 2, verifica-se que, de 2004 a 2013, as relações crédito / PIB elevaram-se mais nas Grandes Regiões (exceto Norte em pontos percentuais, não em percentagem) do que no estado de São Paulo!

\section{Quadro 2}

\begin{tabular}{|c|c|c|c|c|c|c|c|c|c|c|c|}
\hline \multirow{2}{*}{\begin{tabular}{|c} 
Grandes Reglöes / \\
UF
\end{tabular}} & \multicolumn{10}{|c|}{ Crédito / PIB de Brasil, Grandes Regiões e São Paulo (em \%) } & \multirow{3}{*}{$\begin{array}{r}\begin{array}{c}\text { Elev. em } \\
\text { pontos perc. }\end{array} \\
\mathbf{2 7}\end{array}$} \\
\hline & 2004 & 2005 & 2006 & 2007 & 2008 & 2009 & 2010 & 2011 & 2012 & 2013 & \\
\hline Brasil & 23 & 24 & 27 & 32 & 38 & 41 & 42 & 45 & 47 & 49 & \\
\hline Norte & 15 & 17 & 19 & 23 & 27 & 30 & 30 & 32 & 35 & 35 & 20 \\
\hline Nordeste & 18 & 20 & 22 & 27 & 32 & 37 & 40 & 45 & 46 & 49 & 31 \\
\hline Sudeste & 23 & 24 & 27 & 32 & 38 & 42 & 42 & 44 & 47 & 48 & 25 \\
\hline Sāo Paulo & 25 & 26 & 29 & 33 & 39 & 41 & 41 & 44 & 46 & 47 & 22 \\
\hline Sul & 25 & 29 & 33 & 37 & 43 & 45 & 47 & 51 & 55 & 55 & 30 \\
\hline Centro-Oeste & 25 & 27 & 30 & 34 & 38 & 39 & 41 & 45 & 48 & 54 & 29 \\
\hline
\end{tabular}

fonte: Banco Central e Contas Regionais do IBGE (2014). elaboração: Fernando Nogueira da Costa (2016).

Como explicar essa surpresa? Na próxima seção, concluirei com uma explicação alternativa para as interações entre os múltiplos componentes de um sistema financeiro complexo que promovem uma dependência de trajetória indeterminada a priori. Decisões cruciais de agentes públicos podem buscar uma regulação ou reorientação dessa trajetória. 
Para concluir esta análise empírica, todos esses números parecem demonstrar a emergência de um inesperado fenômeno macroscópico a partir de decisões microscópicas ao longo de um período de treze anos de governo com atuação social-desenvolvimentista de seus bancos federais. As interações dos diversos componentes do SFN em termos tanto de empréstimos quanto de captações resultaram em algo inesperado segundo as previsões deduzidas das análises com dados do período anterior ao ano de 2004. O Quadro 3 indica uma ligeira desconcentração regional do crédito entre o centro e a periferia de janeiro de 2004 a janeiro de 2016.

\section{Quadro 3}

\begin{tabular}{|c|c|c|c|c|c|c|c|}
\hline $\begin{array}{l}\text { Partici } \\
\text { Data }\end{array}$ & $\begin{array}{l}\text { açóes do } \\
\text { São Paulo }\end{array}$ & $\begin{array}{l}\text { tado } \\
\text { Norte }\end{array}$ & $\begin{array}{l}\text { Săo Pau } \\
\text { Nordeste }\end{array}$ & $\begin{array}{l}\text { Dlo e Grandes } \\
\text { Centro-Oeste }\end{array}$ & $\begin{array}{l}\text { Regloes } \\
\text { Sudeste }\end{array}$ & $\begin{array}{l}0 \mathrm{Cr} \\
\text { Sul }\end{array}$ & Total \\
\hline jan/04 & 38 & 3 & 10 & 9 & 59 & 19 & 100 \\
\hline $\mathrm{jan} / 16$ & 30 & 4 & 13 & 11 & 55 & 18 & 100 \\
\hline
\end{tabular}

fonte: BCB (2016).

\section{Considerações finais: papel dos bancos públicos frente à desigualdade re- gional}

Os fatos e os dados apresentados neste artigo sugerem que a organização do espaço geoeconômico brasileiro influenciou o crédito, recentemente, e não o contrário. Analistas esperavam um processo cumulativo de realimentação da concentração econômica regional devido à centralização financeira ocorrida entre 1995-2002 por causa da crise bancária, da privatização de bancos estaduais, da desnacionalização de bancos e da reestruturação patrimonial de bancos públicos federais, tendo como contrapartida eles adotarem uma ótica pró-mercado.

Essa predição não se cumpriu. A desigualdade regional em riqueza financeira pessoal e corporativa determinou a escolha das sedes dos bancos particulares. Porém, a busca de correção dessa desigualdade socioeconômica, entre outras políticas públicas, por meio de transferência de renda compensatória, elevação real do salário-mínimo e investimentos em infraestrutura e logística, influenciou o direcionamento de crédito dos bancos públicos federais após 2003 .

Em termos de escala nacional, os maiores bancos privados, com oferta de recursos livres, isto é, não direcionados a priori, responderam à demanda efetiva por crédito, que cresceu na região periférica com a ampliação do mercado consumidor interno resultante de políticas públicas.

Em suma, os analistas pós-keynesianos, devido à teoria da preferência pela liquidez dos bancos, esperavam uma dependência de trajetória com retroalimentação que desigualaria ainda mais as rendas regionais. Porém, inovações como políticas públicas progressistas buscaram contrapor-se a essa trajetória de concentração de renda regional perversa socialmente.

Elas não conseguem determinar, de maneira irreversível, o fim do processo de desigualdade regional. Isso porque dependeria da manutenção da frágil democracia brasileira a continuidade das políticas sociais ativas que repercutiam na ampliação do mercado interno, tanto de consumo, quanto de financiamento. 
Neste artigo, portanto, foi testada e falseada a hipótese de que há uma teoria pós-keynesiana monoeconômica sobre bancos, atemporal e onipresente, isto é, sempre válida em todos os lugares. Em nível de abstração menor, as características institucionalistas (origens do capital ou tipos de controle acionário) dos bancos são influentes em seus desempenhos. No Brasil, nem todos os bancos são orientados por expectativas em relação ao mercado, ou seja, por "preferência pela liquidez". Mais da metade do mercado de crédito brasileiro tem sido orientado por políticas públicas, executadas por bancos públicos, contra as expectativas pessimistas.

\section{Referências}

ANBIMA. ASSOCIAÇÃO BRASILEIRA DAS ENTIDADES DOS MERCADOS FINANCEIRO E DE CAPITAIS. Boletim de Private e Varejo. Disponível em: http://www.anbima.com.br/pt_br/informar/relatorios/varejo-private-e-gestores-de-patrimonio/boletim-de-private-e-varejo/boletim-de-private-e-varejo.htm. Acesso em: 20 jun. 2017.

AMADO, A. Moeda, financiamento, sistema financeiro e trajetórias de desenvolvimento regional desigual: a perspectiva pós-keynesiana. Revista de Economia Política, São Paulo, v. 18, n. 1, p. 76-89, jan./mar. 1998.

A questão regional e o sistema financeiro no Brasil: uma interpretação pós-keynesiana. Estudos Econômicos, São Paulo, v. 27, n. 3, p. 417- 440, set./dez. 1997.

BCB. BANCO CENTRAL DO BRASIL. Nota para imprensa. Política Monetária e Operações de Crédito do SFN, 24 fev. 2016. Disponível em: https://www.bcb. gov.br/htms/notecon2-p.asp. Acesso em: 14 jun. 2017.

Dados Selecionados de Entidades Supervisionadas. Disponível em: https:// www3.bcb.gov.br/informes/relatorios?lingua=pt. Acesso em: 14 jun. 2017.

SCR - Sistema de Informações de Crédito. Disponível em: http://www.bcb. gov.br/pt-br/\#!/n/SCR. Acesso em: 14 jun. 2017.

SGS - Sistema Gerenciador de Séries Temporais. Disponível em: https:// www3.bcb.gov.br/sgspub/localizarseries/localizarSeries.do?method=prepararTelaLoc alizarSeries. Acesso em: 14 jun. 2017.

Relatório de Poupança. Disponível em: http://www.bcb.gov.br/Pre/Salalmprensa/port/ poupanca.asp. Acesso em: 20 jun. 2017.

CAVALCANTE, A.; CROCCO, M. A.; JAYME JR., F. G. Preferência pela liquidez, sistema bancário e disponibilidade de crédito regional. Belo Horizonte: Cedeplar/Face/UFMG, 2004.

COSTA, F. N. Atuação anticíclica dos bancos públicos brasileiros. Campinas: TDIE-Unicamp 258, set. 2015.

Brasil dos Bancos. São Paulo: Edusp, 2012. 
. (Im)propriedades da moeda. Revista de Economia Política, São Paulo, v. 13, n.

2, p. 61-75, 1993.

COSTA, F. N.; MARINHO, M. R. N. Bancos no estado de São Paulo: 1988-93. In: ARAÚ_JO, M. F. I.; GUIZZARDI FILHO, O. (Coord.). Estratégias recentes no terciário paulista. São Paulo: Análise E Ensaios Seade, 1995. p. 49-92.

COSTA, F. N.; PINTO, G. M. A. Impactos da pressão para concorrência bancária no mercado de crédito brasileiro. Campinas: TDIE-Unicamp 215, fev. 2013.

CROCCO, M. A. $\bigcirc$ financiamento do desenvolvimento regional no Brasil: diagnósticos e propostas. Agenda Brasil, p. 297-332, 2004.

et al. The behauviour of liquidity preference of banks and public and regional development: the case of Brazil. Journal of Post Keynesian Economics, Nova York, v. 28, n. 2, p. 217-240, 2005.

et al. Liquidity Preference of Banks and Public and Regional Development: the case of Brazil. - texto para discussão. Belo Horizonte: UFMG/Cedeplar, 2004.

et al. Desenvolvimento econômico, preferência pela liquidez e acesso bancário: um estudo de caso - texto para discussão n. 192. Belo Horizonte: UFMG/ Cedeplar, 2003.

CROCCO, M.; FIGUEIREDO, A. T. L. Differentiated Bank Strategies Across The Territory: An Exploratory Analysis. Belo Horizonte: Cedeplar/Face/UFMG, 2009.

DIXON, R.; THIRLWALL, A. P. A Model Of Regional Growth-Rate Differences On Kaldorian Lines. Oxford Economic Papers, v. 27, n. 2, p. 201-214, jul. 1975.

DOW, S. C. The Stages of Banking Development and the Spatial Evolution of Financial Systems. In: MARTIN, R. (Ed.). Money and the Space Economy. Chichester, UK: Wiley-Blackwell, 1999. p. 31-48.

Money and the Economic Process. Cheltenham, UK: Edward Elgar, 1993.

; RODRÍGUEZ-FUENTES, C. EMU and the Regional Impact of Monetary Policy. Regional Studies, v. 37, n. 9, p. 969-980, dec. 2003.

. Regional Finance: A survey. Regional Studies, v. 31, n. 9, p. 903-920, 1997.

FERNANDES, M. et al. Sistema financeiro e desenvolvimento regional: notas exploratórias. In: PAULA, L. F; OREIRO, J. L. Sistema financeiro: uma análise do sistema bancário brasileiro. Rio de Janeiro: Elsevier, 2007. p. 285-305.

FREITAS, A. P. G.; DE PAULA, L. F. R. Concentração regional do crédito e consolidação bancária no Brasil: uma análise pós-real. Revista Economia, Brasília, DF, v. 11, n. 1, p. 97-123, jan./abr. 2010.

IBGE. INSTITUTO BRASILEIRO DE GEOGRAFIA E ESTATÍSTICA. Contas Regionais do Brasil: 2010-2014. Rio de Janeiro: IBGE, 2014. Disponível em: http://www. ibge.gov.br/home/estatistica/economia/contasregionais/2014/. Acesso em: 20 jun. 2017. 
JAYME JR., F. G.; CROCCO, M. A. (Org.). Bancos públicos e desenvolvimento. Brasilia, DF: Ipea, 2010. p. 105-150.

Política Fiscal, disponibilidade de crédito e financiamento de políticas regionais no Brasil. Belo Horizonte: Face/Cedeplar/UFMG, maio 2005.

MENEZES, M. S.; CROCCO, M. A. Avaliação das condições de financiamento do desenvolvimento regional: notas preliminares. In: ENCONTRO NACIONAL DA ANPUR, 11., 2005, Salvador. Anais... Salvador, 2005. Disponível em: http://www.anpur.org. br/anaisAbrir/61/1/anais-do-xi-ena. Acesso em: 20 jun. 2017.

MOORE, B. Horizontalists and Verticalists: The Macroeconomics of Credit Money. Cambridge: Cambridge University Press, 1988.

MYRDAL, G. Teoria econômica e regiões subdesenvolvidas. 2. ed. Rio de Janeiro: Saga, 1968.

RODRIGUEZ-FUENTES, C. J. Credit Availability and Regional Development. Regional Science, v. 77, n. 1, p. 63-75, 1998.

SICSÚ, J.; CROCCO, M. A. Em busca de uma teoria da localização das agências bancárias: algumas evidências do caso brasileiro. Economia, Niterói, v. 4, n. 1, p. 85-112, jan./jun. 2003.

TORRES, H. G. Sedes dos grandes grupos econômicos: relevância para as metrópoles brasileiras. 1a Análise Seade, São Paulo, n. 12, mar. 2014. 